\title{
Os estudos do lazer no Brasil - apropriação da obra de Marx e Engels
}

Elza Margarida de Mendonça Peixoto*

\begin{abstract}
Resumo: Balanço da apropriação da obra de Marx e Engels pela produção do conhecimento referente aos estudos do lazer no Brasil, correspondente à análise de 15 estudos que afirmam que Marx elege o trabalho como necessidade e obrigação suprema do indivíduo, sem, no entanto, fazer referência às obras lidas. Destacam-se os estudos e os estudiosos que repetem esta afirmação para, em seguida, debater e comprovar sua inverdade, com o apoio em passagens das obras de Marx e Engels. Destacam-se os desafios que os estudiosos devem enfrentar para promover o avanço da produção do conhecimento acerca da problemática do lazer.
\end{abstract}

Palavras-chave: Atividades de lazer. Estado da arte. Marx. Engels. Marxismo. Bibliografia como assunto.

\section{INTRODUÇÃo}

Gostaria de prenunciar um tempo em que ninguém pergunte se os autores são marxistas ou não, porque os marxistas poderiam então estar satisfeitos com a transformação da história obtida com as idéias de Marx. Mas estamos longe de tal condição utópica: as lutas de classe e de libertação, ideológicas e políticas, do século XX são tais que isso é até inconcebível. Quanto ao futuro previsível, teremos que defender Marx e o marxismo dentro e fora da história, contra aqueles que os atacam dentro do terreno político e ideológico. Ao fazer isso, também estaremos defendendo a história e a capacidade do homem de compreender como o mundo veio a ser o que é hoje, e como a humanidade pode avançar para um mundo melhor (HOBSBAWM, 1998, p. 184).

É de Saviani (1987, p. 51) a afirmação "[...] se não se domina o já conhecido não é possível detectar o não conhecido [...]", que nos leva a concluir que não podemos fazer avançar qualquer campo

\footnotetext{
* Doutora em Educação. Docente da Universidade Estadual de Londrina. Centro de Educação Física e Esportes. Departamento de Estudos do Movimento Humano. Londrina, PR. Brasil. E-mail: emmpeixoto@yahoo.com.br
} 


\section{Artigos Originais Elza Margarida de Mendonça Peixoto}

de conhecimento desconhecendo o estágio de andamento da produção, seus avanços e limites. Trazendo esta orientação para o âmbito da produção do conhecimento referente aos estudos do lazer ${ }^{1}$ no Brasil, especificamente aos estudos que tratam das relações entre lazer/ trabalho, propomo-nos a colocar em discussão seus avanços e limites no que toca à apropriação da obra de Marx e Engels, discutindo as implicações desta apropriação ${ }^{2}$ para os estudos do lazer.

Destacamos que a seleção deste ponto de observação dos estudos do lazer não é sem propósito, pois o levantamento da produção do conhecimento (PEIXOTO, 2007a, 2007b) permitiu localizar, em meio a 2.664 trabalhos disseminados entre os séculos XX e XXI, pelo menos 107 textos de 68 autores que fizeram algum tipo de referência às obras de Marx e Engels em suas discussões. Este dado é indicativo de que os autores que discutem a relação lazer/trabalho vêem-se obrigados a estabelecer posições com relação ao pensamento marxiano e marxista, sejam elas de adesão à obra desses clássicos ou da sua negação enquanto referenciais relevantes para a compreensão da problemática do lazer.

Considerando-se esta constatação, entendemos que está colocado para estes 68 autores o problema do conhecimento da obra de Marx e Engels, cabendo-lhes explicitar em que o conhecimento destes clássicos do pensamento social contribui, ou não, para a compreensão da problemática do lazer na atualidade. Em virtude do espaço disponível para a discussão, neste artigo tratamos da análise dos trabalhos que fazem referência a Marx ou Engels sem referência às obras lidas. Esta exposição é precedida de uma breve descrição dos procedimentos utilizados para o levantamento e dos principais trabalhos localizados.

\footnotetext{
${ }^{1} \mathrm{O}$ recurso às palavras-chave recreação, lazer, lúdico, tempo livre, tempo liberado, tempo disponível, ócio, etc. foi central para a localização dos 2664 trabalhos, aos quais nos referimos rapidamente neste artigo. Optamos por desprezar a multiplicidade de palavras-chave e a multiplicidade de sentidos atribuídos a elas na identificação e na delimitação dos autores que contribuem para a compreensão da problemática do lazer, reunindo todos os trabalhos sob a expressão estudos do lazer.

${ }^{2}$ Essa palavra refere-se ao ato ou efeito de apropriar-se; acomodação; adaptação. Também se refere a tomar como propriedade; arrogar-se a posse de; tomar como próprio ou adequado, conveniente; adequar, adaptar, acomodar. Trata-se, portanto, do processo de apropriação no sentido de tomar como próprio, no sentido de indicar se esta referência é válida ou não para a compreensão da problemática do lazer, no sentido de indicar se trata-se de referência legítima para a apreensão desta problemática ou não, considerando-se a universalidade dos saberes e a abrangência da obra de Marx e Engels. Trata-se de perguntar: até que ponto está sendo feita com qualidade, no que toca ao rigor e à radicalidade?
}

Movimento, Porto Alegre, v. 14, n. 03, p. 87-116, setembro/dezembro de 2008. 


\section{Dados gerais sobre a APROPriação da obra de MarXe Engels PELOS ESTUDOS DO LAZER}

Para a localização e seleção dos textos que apresentam apropriação da obra de Marx e Engels, consideramos a referência a estes autores ou suas obras: (1) nos títulos; (2) nas referências bibliográficas; e/ou (3) no corpo de artigos, livros ou capítulos de livros, trabalhos completos disseminados em periódicos e eventos, e algumas dissertações e teses. ${ }^{3}$ A partir deste primeiro critério, selecionamos 65 autores, que foram, inicialmente, analisados tomando-se por base a referência às fontes. O quadro abaixo permite conhecer os resultados obtidos:

\begin{tabular}{|c|c|c|}
\hline Situação & Autores & Total \\
\hline $\begin{array}{l}\text { Referência a Marx } \\
\text { ou Engels sem } \\
\text { referência às obras } \\
\text { lidas }\end{array}$ & $\begin{array}{l}\text { Amaral (2006); Camargo (1990, 1993, 1998, 2003); Cavalcanti (1984); } \\
\text { Cortella (2003); Dacosta (2003); Werneck (2000, p. 48-49); Gomes } \\
\text { (2003, p. 73- 74; p. 75, nota 26; 2003, p. 75-76); }{ }^{4} \text { Gutierrez (2001); } \\
\text { Marcellino (1983, 1987, 1992); Mwewa (2005); Nascimento (2005); } \\
\text { Reale (1980); Ritter (2003); Salomão, Carmo (2005); Sodré (1938). }\end{array}$ & 15 \\
\hline $\begin{array}{l}\text { Referência a Marx } \\
\text { ou Engels com } \\
\text { referência às obras } \\
\text { lidas }\end{array}$ & $\begin{array}{l}\text { Alves (2006); Andrade (2006); Antunes (1999, 2001); Becker (2002); } \\
\text { Bruhns (2000); Café (2001); Chemin (2003); Costa \& Maia (2003); } \\
\text { Cunha (1987); Faleiros (1979, 1980); Feres Neto (1996, 1997); Freitas } \\
\text { (1995); Gawryszewski (2003); Gebara (1994); Guimarães (2001); Inácio } \\
(1997, \text { 1999); Inácio, Silva, Pereti, Liesenfeld (2005); Isayama \& Moura } \\
(2000) \text {; Leiro (2002a, 2002b); Lopes (1986); Marcassa (2002, 2003a, } \\
\text { 2003b); Marin (1999); Mascarenhas (2000a, 2000b, 2001, 2005a, 2005b); } \\
\text { Mota \& Souza (2000); Navarro (2006); Oliveira (1986, 2001); Oliveira } \\
\text { (2005); Pacheco (1992, 2001); Padilha (1997, 2000, 2003a, 2003b, 2004a, } \\
\text { 2004b, 2006); Palafox (1997); Paro (2003); Pellegrin (2006); Polato } \\
\text { (2004a, 2004b); Sá (2003a, 2003b, 2003c, 2003d); Sadi (1999); Silva } \\
\text { (1997, 1999, 2001); Silva (2003); Silva (2005); Silveira (2003, 2005); } \\
\text { Sousa (2002, 2005); Sousa, Húngaro, Requena, Polato (2000); Sousa, } \\
\text { Severino, Oliveira (2000); Sussekind (1950); Taffarel (2003, 2005); } \\
\text { Valente (1997); Valle (1987); Veronez (2003); Vieitez (2002); Witiczac } \\
\text { (2003); Zingoni (2001). }\end{array}$ & 50 \\
\hline $\begin{array}{l}\text { Não foi possível } \\
\text { avaliar }^{5}\end{array}$ & Finocchio (1993); Gariglio (1995); Santin (1997). & 3 \\
\hline
\end{tabular}

Quadro 1. Correspondência entre referência a Marx e Engels e a referência às obras.

\footnotetext{
${ }^{3}$ Recorremos às dissertações e teses principalmente quando o trabalho do autor apresentava relevância para a pesquisa.

${ }^{4}$ Gomes (2003) e Werneck (2000) são a mesma autora: Christianne Luce Gomes.

${ }^{5}$ Apesar do esforço para adquirir todos os textos, os Anais de eventos em que foram disseminados estes trabalhos listados por Guimarães não foram localizados.
}

Movimento, Porto Alegre, v. 14, n. 03, p. 87-116, setembro/dezembro de 2008. 


\section{Artigos Originais Elza Margarida de Mendonça Peixoto}

Dos 65 autores avaliados, $15(23,1 \%)$ não apresentaram referência às fontes contra $50(76,9 \%)$ que apresentaram. Neste artigo, discutiremos as características da apropriação da obra de Marx e Engels pelos quinze autores que não fazem referência às fontes diretas nas quais se apóiam para afirmar ou negar a contribuição da obra de Marx e Engels para a compreensão da problemática do lazer.

\section{CARACTERÍSTICAS DA APROPRIAÇÃo SEM REFERÊNCIA ÀS OBRAS LIDAS}

De maneira geral os autores que não fazem referência às obras lidas pronunciam-se negando a contribuição de Marx para a compreensão da problemática do lazer, com raríssimas referências a Engels. ${ }^{6}$ Tal negação apóia-se na tese de que as idéias de Marx expressam uma exaltação e mitificação do trabalho, cuja raiz está, por sua vez, localizada nas transformações econômicas que ocorrem nos séculos XVIII e XIX. Esta idéia é construída de modo espalhado entre os diversos autores, configurando-se como uma verdade que é multiplicada e disseminada pelos especialistas renomados. Nos trabalhos reunidos encontramos:

- Alto índice de referência aos autores remetendo-se a comentaristas, ou sem referência às obras consultadas, o que denota ausência de apropriação direta, um dos critérios essenciais de qualquer produção científica, ainda mais quando visam à crítica ao autor referido (Da COSTA, 2003):

\begin{abstract}
Munné (1980), [...] diz que no pensamento de Marx não se concebe um tempo separado de trabalho e de lazer, pois estes estão intrinsecamente ligados [...]. Para Marx, somente com o término do trabalho determinado poderá começar o reino da liberdade e o desenvolvimento das forças do ser humano [...]. A utopia é a criação de uma sociedade em que o tempo livre e o tempo de trabalho serão uma só coisa, um só tempo de liberdade (AMARAL, 2006, p. 171-172)
\end{abstract}

Referindo-se à interpretação de Gadotti: "Partindo da visão clássica de ideologia, tal como aparece na

\footnotetext{
${ }^{6}$ É o caso de Camargo, 1998, p. 144.

Movimento, Porto Alegre, v. 14, n. 03, p. 87-116, setembro/dezembro de 2008.
} 
obra de Marx, o autor demonstra que a educação permanente dissimula as desigualdades perante a educação [...] (CAVALCANTI, 1984, p. 74-75).

Quando se aceita como verdadeiro o pensamento de Marx, de que na sociedade burguesa a força de trabalho tornou-se mercadoria e, por isso, o trabalho foi coisificado, então a palavra 'hobby' conduz ao paradoxo de que aquele estado, que se entende como o contrário de coisificação, como reserva de vida imediata em um sistema total completamente mediado, é, por sua vez, coisificado da mesma maneira que a rígida delimitação entre trabalho e tempo livre (ADORNO apud MWEWA, 2005, p. 65).

A cultura é compreendida sob o ponto de vista dos movimentos sociais, alavancado pela luta de classes, respectiva a cada período histórico, aspecto este defendido por Hegel e Marx [...] (CHAUÍ, 1996 apud NASCIMENTO, 2005, p. 3491).

Independente da vertente ideológica, alguns pensadores do início do século XIX apresentaram o que para eles era a função do lazer. Marx atribuía a esse espaço de tempo a possibilidade de desenvolvimento humano; [...] Engels postulava a diminuição da jornada de trabalho a fim de que um maior número de pessoas pudesse participar dos negócios gerais da sociedade (DUMAZEDIER apud RITTER, 2003, p. 2).

- Apresentação de Marx como um ideólogo que elege o trabalho como necessidade e obrigação suprema do indivíduo, concorrendo para uma atitude de conformismo e resignação face às condições técnicas do trabalho:

As religiões (malgrado uma certa resistência da Igreja Católica) e ideologias (tanto Marx como Adam Smith concordaram na eleição do trabalho como necessidade e obrigação suprema do indivíduo) dominantes nos últimos duzentos anos, concorreram para uma atitude de conformismo e resignação em face às condições técnicas do trabalho (CAMARGO, 1990, p. 70). Tanto Adam Smith, o primeiro teórico do capitalismo, como Karl Marx, o principal teórico do comunismo, não viam para a sociedade humana

Movimento, Porto Alegre, v. 14, n. 03, p. 87-116, setembro/dezembro de 2008. 


\section{Artigos Originais Elza Margarida de Mendonça Peixoto}

outra alternativa senão o trabalho (CAMARGO, 1998, p. 146-148).

No decorrer da história da filosofia, a questão do trabalho sempre se mostra presente [...]. Um aprofundamento mais analítico dessas concepções, não necessariamente contraditório, é encontrado na teoria marxista, que coloca o trabalho numa das posições centrais das relações sociais, enaltecendo 'o princípio do trabalho como essência genérica do homem'. [...] Uma síntese das proposições de Marx, com base nessas hipóteses do materialismo histórico, nos é oferecida por Ernest Fisher [...] 'a ação da liberdade real é justamente o trabalho'. [...] a evolução histórica da interpretação do trabalho passou de um extremo de anulação para outro oposto de sublimação, da servidão para a libertação, de ação eventual para processo de transformação social (DA COSTA, 2003, p. 12 - grifo nosso).

[...] o papel da categoria trabalho é central tanto na obra de Marx, como na de Weber e Durkheim, o que os tornaria a todos conservadores com relação a modelos explicativos que não privilegiassem a categoria trabalho social. Esta coincidência nos três grandes clássicos da sociologia não é acidental, mas determinada pelo momento histórico em que suas obras foram escritas[...] (OFFE apud GUTIERREZ, 2001, p. 93)

- Comparação de Marx a Adam Smith, no que toca à falta de visão de alternativas para a sociedade que não passassem pelo trabalho. Marx apresenta uma dimensão positiva frente a Smith, na medida em que permite denunciar a divisão da sociedade entre os que dominavam os meios de produção e o lucro e os explorados de toda sorte, incentivando a organização dos explorados a por meio da revolução se apropriarem dos meios de produção e dos benefícios do seu próprio trabalho. Mas, para Marx, o trabalho continuava sendo a principal necessidade do homem. O lúdico era para o futuro. O tempo livre que ainda sobrava deveria ser dedicado a coisas úteis, como a política:

O trabalho é chato, como a escola é chata, para a imensa maioria das pessoas. A sociedade incorporou

Movimento, Porto Alegre, v. 14, n. 03, p. 87-116, setembro/dezembro de 2008. 
ao absurdo o conceito de que o trabalho é tudo. Adam Smith e Karl Marx, por exemplo, diziam a mesma coisa e prometiam a felicidade neste mundo, mas só depois que o futuro felizardo desse duro a vida toda, dezesseis horas por dia, todos os dias da semana. Lamentando que os marxistas não tenham aproveitado a tradição do pensamento de Paul Lafargue, genro de Marx, que, no seu manifesto, $O$ direito à preguiça, criticava a tolice dos operários que lutavam pelo direito ao trabalho em vez de lutar abertamente, sem subterfúgios, pelo direito aos mesmos privilégios de lazer dos patrões (CAMARGO, 1993, p. 8-9).

O trabalho é a primeira finalidade do homem, eis o que diziam, ao mesmo tempo Adam Smith e Karl Marx, além dos padres e pastores, dos políticos, não obstante as vozes fortes mas ainda assim inaudíveis de Fourier, Lafargue, na França, Noailles Thoreau nos Estados Unidos (CAMARGO, 2003, p. 36).

- Freqüente contraposição entre o pensamento de Marx e de Lafargue, na qual o segundo é apontado como um membro da família do primeiro que se contrapõe à eleição do trabalho como necessidade e obrigação suprema do indivíduo, e é, por esta razão, o primeiro a fazer a defesa do direito à preguiça:

Tudo se passava de forma tão hipócrita que Paul Lafargue (1842-1911), genro do pensador alemão Karl Marx (1818-1883), escreveu um manifesto chamado $O$ direito à preguiça, em que ridicularizava os operários da indústria nascente, que trabalhavam 15 horas por dia e reivindicavam o direito ao trabalho, mesmo em tais condições[...] (CAMARGO, 1998, p. 31).

Embora o que se verifique atualmente seja a impossibilidade de referência ao marxismo como um pensamento unitário, pelas várias correntes que a denominação abriga, é certo que, em quase todas elas, ocorre a exaltação do trabalho. Seja como for, ironicamente, é o genro de Marx, Paul Lafargue, quem corajosamente elabora uma das primeiras sistematizações defendendo o lazer dos operários, em fins do século

Movimento, Porto Alegre, v. 14, n. 03, p. 87-116, setembro/dezembro de 2008. 


\section{Artigos Originais Elza Margarida de Mendonça Peixoto}

XIX, opondo-se não somente à mitificação do trabalho, como cerceamento da vida do trabalhador, mas também ao usufruto dos efeitos da exploração, pelos dominantes, também cerceados na sua vida em virtude das obrigações impostas pelo consumo (MARCELLINO, 1987, p. 23).

Segundo o prefácio escrito por Marilena Chauí que introduz a $2^{\mathrm{a}}$ Edição da obra $O$ direito à preguiça (LAFARGUE, 1999), Paul Lafargue redigiu vários textos sintetizando as idéias de Marx com o objetivo de divulgá-las entre os operários franceses revolucionários, sendo um dos maiores responsáveis pelo surgimento do marxismo francês na transição do século XIX para o século XX. Porém, considerando principalmente as questões que envolvem o lazer e a máquina, Oliveira (2002) indica que no livro $O \mathrm{di}$ reito à preguiça Lafargue diverge em muitos pontos das idéias marxistas (GOMES, 2003, p. 74, nota 26). Em outra passagem: "Os operários reivindicavam a redução da jornada diária de trabalho para oito horas, mas para Lafargue (1999) apenas três seriam o bastante. $\mathrm{O}$ autor propõe diminuir a quantidade de tempo dedicada à produção, o que não coincide inteiramente com as idéias de Marx, para quem o capitalismo proporciona o desenvolvimento das forças produtivas, sendo este necessário para a implantação do socialismo. Para Lafargue, em contrapartida, era a grande quantidade de tempo destinada ao trabalho capitalista que estava privando o proletariado de exercer o direito à preguiça. Segundo a visão do autor, a preguiça era mil vezes mais nobre e mais sagrada que os Direitos do homem arquitetados pela burguesia. Tal argumentação sobre a preguiça ecoou como um verdadeiro ultraje à lógica da produtividade, almejada nos centros urbanos e industrializados com o intuito de combater o ócio (GOMES, 2003b, p. 75-76).

Não é por acaso que Paul Lafargue, um francocubano casado com Laura, filha de Karl Marx, e fundador do Partido Operário Francês, foi pouco compreendido na ironia contida em alguns dos seus escritos. Em 1883, quando todo o movimento social reivindicava tenazmente o direito ao trabalho, isto é, o término de qualquer forma de desocupação, o

Movimento, Porto Alegre, v. 14, n. 03, p. 87-116, setembro/dezembro de 2008. 
genro de Marx publicou Direito à Preguiça, uma desnorteante e - só na aparência - paradoxal análise sobre a alienação e exploração humana no sistema capitalista (CORTELLA, 2003, p. 2).

- Alusão ao trabalho enquanto uma das configurações promovidas pelas mudanças e transformações, devidas, em parte, à implantação do modo de produção capitalista entre os séculos XVIII e XIX, quando se difunde a idéia de que o trabalho é o que permite, efetivamente, aumentar a riqueza das nações, acompanhada da alusão de que, nesse período, os homens são animalizados a ponto de comprometer a afirmação, atribuída a Marx, de que o trabalho é o que diferencia o homem do animal:

Assim sendo, o século XVIII na Europa, é um dos momentos mais expressivos de nossa história. Ele configurou a sociedade, a política, a economia, a cultura, a educação, o trabalho e o próprio homem. Essas mudanças são devidas, entre outros aspectos, às transformações geradas com a implantação do modo de produção capitalista, conferindo novos contornos ao lazer. Esses contornos passam a ser delineados, sobretudo, em função de um tempo de não-trabalho, ou seja, de um tempo que pudesse ser estabelecido em contraponto ao trabalho produtivo. A idéia de que o trabalho é o que permite, efetivamente, aumentar a riqueza das nações se difundiu rapidamente no decorrer do século XIX. São alterados os antigos laços de subordinação à terra, ao senhor, transformando a grande maioria em trabalhadores livres - livres, evidentemente, para vender a sua força de trabalho a quem pudesse lhes dar emprego. Esse novo pensamento se desenvolve a partir da dominação capitalista e da exploração de mão-de-obra assalariada, comprometendo a noção elaborada por Marx, na qual o trabalho (isto é, a possibilidade de transformação dos objetos e do mundo) é o que diferencia, fundamentalmente, o homem do animal, restando aos assalariados uma única opção: o trabalho alienado (ENRIQUEZ, 1999 apud WERNECK, 2000, p. 48-49).

- Alusão a Marx e aos marxistas, afirmando-se que tecem críticas ao lazer, destacando-se a existência de diferenças de posição

Movimento, Porto Alegre, v. 14, n. 03, p. 87-116, setembro/dezembro de 2008. 


\title{
96 Artigos Originais Elza Margarida de Mendonça Peixoto
}

entre estes, que geram duas correntes, ora privilegiando o trabalho, ora privilegiando o tempo fora do trabalho para a realização humana. Afirma-se encontrar em Marx os dois gêneros, denunciando-se o predomínio, com muito peso, da primeira corrente:

\begin{abstract}
As críticas ao lazer são dirigidas também pelos marxistas. Muito embora os pensadores dessa linha estejam divididos em duas correntes, uma privilegiando o trabalho e outra, o tempo fora do trabalho para a realização humana, uma vez que em Marx se encontram textos dos dois gêneros, predomina com muito peso a primeira corrente (MARCELLINO, 1983, p. 23).
\end{abstract}

- Alusão a Marx e aos marxistas como difusores da exaltação e da mitificação do trabalho (MARCELLINO, 1987);

- Alusão a uma comunhão em um mesmo credo produtivista, entre capitalistas e socialistas; tal credo produtivista é atribuído a Karl Marx quando este, rompendo com o chamado socialismo utópico, pretendeu firmar a emancipação do proletariado sob as coordenadas da produção:

Tão forte se tornou a projeção do trabalho como categoria histórico-econômica - tanto sob o prisma capitalista, como sob o enfoque socialista - que ele passou a ocupar o centro do cenário cultural, passando a ser apreciado, em função dele, o tempo que significativamente se denomina repouso ou descanso, diário, semanal ou anual, ou que sobrevém com a 'aposentadoria'. De modo geral, os tratadistas do Direito do Trabalho ainda não se emanciparam desse prisma hermenêutico, quando analisam, por exemplo, o problema das férias, entendidas sempre como uma pausa entre um período e outro do trabalho. A mesma mentalidade preside a elaboração dos textos legislativos, sob o domínio avassalador de uma visão produtivista da vida social, ponto de vista em que, paradoxalmente, capitalistas e socialistas se encontram desde quando Karl Marx, rompendo com o chamado socialismo utópico, pretendeu firmar a emancipação do proletariado sob as coordenadas da produção, a qual, a seu ver, deve deixar de ser individual para converter-se em produção socializada, ou, por melhor dizer, confiada ao Estado como

Movimento, Porto Alegre, v. 14, n. 03, p. 87-116, setembro/dezembro de 2008. 
expressão da nova classe dominante, o proletariado. Capitalismo e socialismo comungam, pois, no mesmo credo produtivista de apologia do trabalho, variando, é claro, quanto aos meios e processo de obter-se o máximo de produção, para alcançar-se o máximo de riqueza partilhável. Não é sem motivo, aliás, que a obra capital de Marx não se denomina $O$ Trabalho mas sim $O$ Capital. O certo é que, aquém e além da chamada cortina de ferro, a que se acresce hoje a cortina de bambu (sem que este termo implique qualquer sentido depreciativo ao comunismo chinês) a idéia dominante é a da tônica posta no valor do trabalho, admitindo-se, via de regra, que o homem só deve descansar para recuperar forças e voltar ao seu trabalho (REALE, 1980, p. 116).

- Apresentação de Marx como o idealizador da luta de classes (SODRÉ, 1938);

- Indicação de intenção de estudos futuros do pensamento de Marx (SALOMÃO; CARMO, 2005).

As constatações acima remetem a duas ordens de questões: em primeiro lugar, faz-se necessário perguntar se estas afirmações correspondem à verdade, no sentido da força motriz da produção do conhecimento científico. Posteriormente, faz-se necessário explicitar as conseqüências dessas constatações para a formação profissional e a produção do conhecimento e do campo de saber em construção, que estamos, genericamente, nomeando como estudos do lazer.

\section{Dıscussão}

Primeiramente, as afirmações freqüentes entre os estudiosos do lazer que fazem referência a Marx e Engels sem referir-se a obras diretas por eles lidas escondem o profundo desconhecimento quanto: (1) à obra original de Marx e Engels, ${ }^{7}$ (2) às matrizes históricas e filosóficas que sustentam essa obra; ${ }^{8}$ (3) ao contexto histórico, econômico e político em que ela é elaborada; ${ }^{9}$ e (4) aos seus desdobramentos, no

\footnotetext{
${ }^{7}$ Bottomore (2001, p. 406-411); Marx e Engels (1980, 1981; 1982a; 1982b; 1985).

${ }^{8}$ Lenin (1978); Engels (1979; 2000; s/d); Marx (2005); Marx e Engels (1980).

${ }^{9}$ Roces $(1981 ; 1982)$.

Movimento, Porto Alegre, v. 14, n. 03, p. 87-116, setembro/dezembro de 2008.
} 


\section{Artigos Originais Elza Margarida de Mendonça Peixoto}

que toca (a) à implementação e experimentação, em alguns países, de algumas teses nela defendidas, gerando o chamado bloco socialista; (b) à sua absorção entre os diferentes pensadores que a desenvolvem, configurando o que chamamos, hoje, marxismo. ${ }^{10}$

Somente o não entendimento das bases que sustentam a Concepção Materialista e Dialética da História permite afirmar que Marx elege o trabalho como necessidade e obrigação suprema do indivíduo. Marx não elege nem inventa o trabalho; ele constata o trabalho como a atividade vital do homem, uma condição da existência humana, uma necessidade do gênero (MARX, 1980). Neste caso, está em ação o pressuposto da anterioridade da matéria em relação ao pensamento, ${ }^{11}$ algo que os idealistas têm imensas dificuldades para compreender. Sob o enfoque materialista, as explicações míticas perdem centralidade, e as condições que permitem a produção e a reprodução da existência humana a assumem - o trabalho é ontologicamente a atividade vital que permite a produção e a reprodução da existência humana. Para Marx e Engels - que recordam que, para fazer história, os homens têm de estar vivos e que para estar vivos necessitam produzir e reproduzir sua existência -, trata-se de reconhecer e denunciar como os homens estão produzindo e reproduzindo sua existência no modo capitalista de produção.

A afirmação de que Marx elege o trabalho como necessidade e obrigação suprema do indivíduo confunde - e propõe uma fusão entre - a ideologia burguesa ${ }^{12} \mathrm{com}$ a profunda análise marxiana do modo como se processa a produção da existência dos homens no modo capitalista de produção. Marx está combatendo essa ideologia burguesa em vários de seus trabalhos escritos a partir da década de 40. Entre eles, estão os Debates sobre a lei castigando os roubos de lenha (1842), os diversos apontamentos que compõem os Manuscritos de 1848, inclusive $O$ trabalho estranhado, os Grundrisse (1857-1858) e todo $O$ Capital (1867).

Nesta direção, trata-se de uma distorção grotesca a afirmação freqüente acerca de diferenças entre Marx e Lafargue,$^{13}$ no que

\footnotetext{
${ }^{10}$ Anderson (1989).

${ }^{11}$ Marx e Engels (1980; 1993)

${ }^{12}$ A religião do trabalho, tal como a define Lafargue (1980)

${ }^{13}$ LAFARGUE (In: FROMM, 1975, p. 190-206).

Movimento, Porto Alegre, v. 14, n. 03, p. 87-116, setembro/dezembro de 2008.
} 
tange à relevância que atribuem ao tempo livre do trabalho. A principal diferença entre as discussões realizadas por Marx e Lafargue ${ }^{14}$ - e se trata sempre de uma comparação desigual, na medida em que falamos a partir de uma única obra do segundo em comparação ao conjunto da obra do primeiro - é que o segundo escreve um panfleto que visava mobilizar a classe trabalhadora contrapondo ao elogio do trabalho abnegado propagado pelo liberalismo burguês, um dos sete pecados capitais: ${ }^{15}$ a preguiça. Lafargue acentua a superação da condição de exploração em que viviam os trabalhadores como uma simples questão de vontade coletiva, ousando imaginar as várias possibilidades abertas caso obtivessem a redução da jornada de trabalho para 3 ou 4 horas. Em Marx, a prisão social do trabalho alienado é explicada em seu desenvolvimento histórico, e é apenas dentro destas condições, historicamente determinadas e em movimento de transformação, que os trabalhadores podem conseguir revolucionar sua situação.

Aqueles que conhecem a obra de Marx, certamente, perceberam sua imensa preocupação com a animalização do homem nas relações de produção capitalistas. O autor denunciava, já nos Manuscritos de 1848, que, neste modo de produção da existência, os homens são impedidos de desenvolver suas potencialidades de gênero, e que o trabalhador se sente livremente ativo só ainda em suas funções animais (MARX apud FERNANDES, 1989, p. 154). Para Marx - um materialista - o trabalho é a atividade vital do homem $(1989$, p. 155) que, no modo capitalista de produção, conforma-se como atividade alienada/estranhada, atividade na qual o homem distancia-se das potencialidades do gênero humano, reduzido às funções animais (comer, beber, procriar), tomadas como fins últimos e exclusivos da existência humana.

Nas próprias palavras de Marx:

$\mathrm{Na}$ medida em que o trabalho alienado aliena do homem 1. a natureza e 2. a si mesmo, a sua função ativa própria, a sua atividade vital, aliena do homem

\footnotetext{
${ }^{14} \mathrm{E}$, neste caso, é freqüente a comparação de Marx, tomado como o conjunto de sua obra, com um único texto de Lafargue, conhecido como $O$ direito à preguiça (1880), o que se constitui, mais uma vez, em um erro primário no âmbito da produção do conhecimento científico. ${ }^{15}$ Chauí (1999), Lafargue (1980), Lafargue (1975).

Movimento, Porto Alegre, v. 14, n. 03, p. 87-116, setembro/dezembro de 2008.
} 


\section{Artigos Originais}

o gênero; lhe faz da vida do gênero um meio de vida individual. Em primeiro lugar aliena a vida do gênero e a vida individual, e em segundo lugar faz da última, em sua abstração um fim da primeira, igualmente na sua forma abstrata e alienada.

Pois em primeiro lugar o trabalho, a atividade vital, a vida produtiva mesma aparece ao homem só como um meio para satisfazer uma necessidade, a necessidade de manutenção da existência física. Mas a vida produtiva é a vida do gênero. É a vida engendradora de vida. No tipo de atividade vital jaz o caráter inteiro de uma species, o seu caráter genérico, e a atividade consciente livre é o caráter genérico do homem. A vida mesma aparece só como meio de vida.

$\mathrm{O}$ animal é imediatamente um com a sua atividade vital. Não se distingue dela. É ela. O homem faz da sua atividade vital mesma um objeto do seu querer e da sua consciência. Tem atividade vital consciente. Não é uma determinidade com a qual ele conflua imediatamente. A atividade vital consciente distingue o homem imediatamente da atividade vital animal. É precisamente só por isso que ele é um ser genérico. Ou ele só é um ser consciente, isto é, a sua própria vida lhe é objeto, precisamente porque é um ser genérico. Só por isto a sua atividade é atividade livre. O trabalho alienado inverte a relação de maneira tal que precisamente porque é um ser consciente o homem faz da sua atividade vital, da sua essência, apenas um meio para a sua existência.

No engendrar prático de um mundo objetivo, no trabalhar a natureza inorgânica o homem se prova como um ser genérico consciente, isto é, um ser que se relaciona com o gênero como a sua essência própria ou se relaciona consigo como ser genérico. Claro que o animal também produz. Constrói um ninho, moradas para si, tal como a abelha, castor, formiga, etc. Só que produz apenas o de que precisa imediatamente para si ou seu filhote; produz unilateralmente, ao passo que o homem produz universalmente; produz apenas sob o domínio da necessidade física imediata, ao passo que o homem produz mesmo livre da necessidade física e só produz verdadeiramente sendo livre da mesma; só produz a si mesmo, ao passo que o homem reproduz a natureza inteira; o seu produto pertence imediatamente ao seu corpo

Movimento, Porto Alegre, v. 14, n. 03, p. 87-116, setembro/dezembro de 2008. 
físico, ao passo que o homem se defronta livre com o seu produto. $\mathrm{O}$ animal forma só segundo a medida e a necessidade da species à qual pertence, ao passo que o homem sabe produzir segundo a medida de qualquer species e sabe em toda parte aplicar a medida inerente ao objeto; por isso o homem também forma segundo as leis da beleza.

Portanto, é precisamente ao trabalhar o mundo objetivo que o homem primeiro se prova de maneira efetiva como um ser genérico. Esta produção é a sua vida genérica operativa. Por ela a natureza aparece como a sua obra e a sua realidade efetiva. $\mathrm{O}$ objeto do trabalho é portanto a objetivação da vida genérica do homem: ao se duplicar não só intelectualmente tal como na consciência, mas operativa, efetivamente e portanto ao se intuir a si mesmo num mundo criado por ele. Por conseguinte, ao arrancar do homem o objeto de sua produção, o trabalho alienado lhe arranca a sua vida genérica, a sua objetividade genérica efetivamente real e transforma a sua vantagem ante o animal na desvantagem de lhe ser tirado o seu corpo inorgânico, a natureza (MARX apud FERNANDES, 1989, p. 155-157).

Ao constatar o trabalho como a atividade vital do gênero humano, ou seja, a atividade de produção e reprodução da existência do gênero humano, incluída sua dimensão estética, Marx apresenta as armas para denunciar que, no modo capitalista de produção da existência - no qual a sociedade inteira tem que se cindir nas duas classes dos proprietários e dos trabalhadores sem propriedade (MARX, 1989, p. 147) - a classe dos sem propriedade (a classe trabalhadora) está impedida de desenvolver as potencialidades do gênero humano.

É a consciência revolucionária da história ${ }^{16}$ que permite a Marx e Engels, ao fazer a crítica da divisão social do trabalho no modo capitalista de produção, projetar (isto é, planejar) uma outra realidade, passível apenas de ser implementada pela classe trabalhadora organizada segundo seus interesses e necessidades, dentro de condições históricas já dadas: ${ }^{17}$

\footnotetext{
${ }^{16}$ Fernandes (1989, p. 146).

${ }_{17}$ Marx (1978; 1980 - v. 1; 2002); Marx e Engels (1980).

Movimento, Porto Alegre, v. 14, n. 03, p. 87-116, setembro/dezembro de 2008.
} 


\section{Artigos Originais Elza Margarida de Mendonça Peixoto}

Finalmente, a divisão do trabalho oferece-nos o primeiro exemplo do seguinte facto: a partir do momento em que os homens vivem na sociedade natural, desde que, portanto, se verifica uma cisão entre o interesse particular e o interesse comum, ou seja, quando a actividade já não é dividida voluntariamente mas sim de forma natural, a acção do homem transforma-se para ele num poder estranho que se lhe opõe e o subjuga, em vez de ser ele a dominá-la. Com efeito, desde o momento em que o trabalho começa a ser repartido, cada indivíduo tem uma esfera de actividade exclusiva que lhe é imposta e da qual não pode sair; é caçador, pescador, pastor ou crítico e não pode deixar de o ser se não quiser perder os seus meios de subsistência. Na sociedade comunista, porém, onde cada indivíduo pode aperfeiçoar-se no campo que the aprouver, não tendo por isso uma esfera de actividade exclusiva, é a sociedade que regula a produção geral e me possibilita fazer hoje uma coisa, amanhã outra, caçar de manhã, pescar à tarde, pastorear à noite, fazer crítica depois da refeição, e tudo isso a meu bel-prazer, sem por isso me tornar exclusivamente caçador, pescador ou crítico. Esta fixação da actividade social, esta petrificação do nosso próprio trabalho num poder objectivo que nos domina e escapa ao nosso controlo contrariando a nossa expectativa e destruindo os nossos cálculos, é um dos momentos capitais do desenvolvimento histórico até aos nossos dias. $\mathrm{O}$ poder social, quer dizer, a força produtiva multiplicada que é devida à cooperação dos diversos indivíduos a qual é condicionada pela divisão do trabalho, não se lhes apresenta como o seu próprio poder conjugado, pois essa colaboração não é voluntária e sim natural, antes lhes surgindo como um poder estranho, situado fora deles e do qual não conhecem nem a origem nem o fim que se propõe, que não podem dominar e que de tal forma atravessa uma série particular de fases e estados de desenvolvimento tão independente da vontade e da marcha da humanidade que é na verdade ela quem dirige essa vontade e essa marcha da humanidade.

Esta "alienação" - para que a nossa posição seja compreensível para os filósofos - só pode ser

Movimento, Porto Alegre, v. 14, n. 03, p. 87-116, setembro/dezembro de 2008. 
abolida mediante duas condições práticas. Para que ela se transforme num poder "insuportável", quer dizer, num poder contra o qual se faça uma revolução, é necessário que tenha dado origem a uma massa de homens totalmente "privada de propriedade", que se encontre simultaneamente em contradição com um mundo de riqueza e de cultura com existência real; ambas as coisas pressupõem um grande aumento da força produtiva, isto é, um estádio elevado de desenvolvimento. Por outro lado, este desenvolvimento das forças produtivas (que implica já que a existência empírica actual dos homens decorre no âmbito da história mundial e não no da vida local) é uma condição prática prévia absolutamente indispensável pois, sem ele, apenas se generalizará a penúria e, com a pobreza, recomeçara paralelamente a luta pelo indispensável e cair-se-á fatalmente na imundície anterior. Ele constitui igualmente uma condição prática sine qua non, pois é unicamente através desse desenvolvimento universal das forças produtivas que é possível estabelecer um intercâmbio universal entre os homens e porque, deste modo, o fenómeno da massa "privada de propriedade" pode existir simultaneamente em todos os países (concorrência universal), tornando cada um deles dependente das perturbações dos restantes e fazendo com que finalmente os homens empiricamente universais vivam de facto a história mundial em vez de serem indivíduos vivendo numa esfera exclusivamente local. Sem isto: 1) o comunismo só poderia existir como fenómeno local; 2) as forças das relações humanas não poderiam desenvolver-se como forças universais e, portanto, insuportáveis, continuando a ser simples "circunstâncias" motivadas por superstições locais; 3) qualquer ampliação das trocas aboliria o comunismo local. O comunismo só é empiricamente possível como acção "rápida" e simultânea dos povos dominantes, o que pressupõe o desenvolvimento universal da força produtiva e as trocas mundiais que lhe estejam estreitamente ligadas.

Para nós, o comunismo não é um estado que deva ser implantado, nem um ideal a que a realidade deva obedecer. Chamamos comunismo ao movimento real que acaba com o actual estado de coisas. As

Movimento, Porto Alegre, v. 14, n. 03, p. 87-116, setembro/dezembro de 2008. 
condições deste movimento resultam das premissas actualmente existentes (MARX e ENGELS, 1980, p. 40-42).

A leitura dos longos trechos que optamos por transcrever acima permite evidenciar que a afirmação de que Marx elege o trabalho como necessidade e obrigação suprema do indivíduo é uma inverdade. Explicitada esta inverdade, trata-se de discutir - buscando o rigor e a radicalidade da crítica à produção do conhecimento referente aos estudos do lazer no Brasil - as implicações da difusão desta interpretação falsa (ou seja, incompatível com as provas) para uma compreensão radical e rigorosa da problemática do lazer, no contexto do modo capitalista de produção e reprodução da existência ao qual estamos subordinados.

Em primeiro lugar, esta afirmação, repetida entre os autores delimitados neste bloco, promove a disseminação da tese segundo a qual a obra de Marx e Engels é inadequada para o estudo da problemática do lazer, na medida em que este estaria privilegiando em seus estudos a esfera do trabalho. Esta afirmação repetida insistentemente conduz à negação das possibilidades oferecidas pela obra de Marx e Engels para a compreensão desta problemática. Nesta direção, os estudiosos que fazem esta afirmação - com evidente desconhecimento de causa como destacamos acima - cumprem o papel ideológico de apagamento da contribuição atualíssima da obra de Marx e Engels para a (1) estruturação da Concepção Materialista e Dialética da História, fundamental para a (2) interpretação do modo como os homens estão produzindo e reproduzindo sua existência nos últimos cinco séculos; e para a (3) compreensão do fato de que a revolução das relações de produção está nas mãos dos homens insatisfeitos com o modo de produção existente. É apenas neste contexto que podemos compreender a prática social, as políticas públicas e a produção do conhecimento referente aos estudos do lazer no Brasil e no mundo.

Aqueles que se apropriam da obra de Marx e Engels, buscando respostas efetivamente revolucionárias, bem como uma leitura de conjunto de seus textos, sabem que a compreensão da problemática do lazer depende da apreensão das relações de produção típicas do

Movimento, Porto Alegre, v. 14, n. 03, p. 87-116, setembro/dezembro de 2008. 
capitalismo, nas quais, tal como já nos mostrou Faleiros (1980), ${ }^{18}$ todas as necessidades humanas (satisfeitas por meio de bens e serviços com diferentes valores de uso) são convertidas em mercadorias a fim de atingir a meta do capitalista: a produção do valor. Frente a tal constatação, duas novas questões se colocam: (1) o enfrentamento, pelos estudos do lazer, do problema da explicação desta prática social, das políticas públicas e da produção do conhecimento, referentes ao lazer no contexto do modo capitalista de produção; (2) a análise da produção do conhecimento referente aos estudos do lazer com vistas à localização das contribuições desta produção, no que toca aos esforços de interpretação desta problemática, com o apoio da obra de Marx e Engels.

Reconhecemos que a primeira questão vem sendo enfrentada pelos estudos do lazer (FALEIROS, 1980; CUNHA, 1987; PADILHA, 2000; 2003; MASCARENHAS, 2005; TAFFAREL 2005; TAFFAREL et al., 2003), no esforço de compreensão dos nexos e contradições da problemática do lazer no modo capitalista de produção, com apoio na obra de Marx e Engels. A segunda questão é decorrência deste primeiro movimento, associado à necessidade de revisão da produção existente a fim de mapear seus progressos e limites. Nesta direção estão os esforços, cujos primeiros resultados estão expostos neste artigo.

${ }^{18}$ Ver também Peixoto (2007c).

Movimento, Porto Alegre, v. 14, n. 03, p. 87-116, setembro/dezembro de 2008. 
106 Artigos Originais Elza Margarida de Mendonça Peixoto

\begin{tabular}{l} 
Leisure Studies in Brazil - Appropriation of \\
Marx's and Engels' Work \\
Abstract: This is an overview on the appropriation of \\
Marx and Engels' work on constructing knowledge \\
and thinking through leisure studies in Brazil. These \\
studies correspond to the analysis of fifteen papers \\
that assume Marx stating work as a necessity and \\
supreme obligation to each Human Being. Such an \\
overview does not mention any reference to Marx \\
and Engels' written studies. Works and scholars are \\
highlighted due to the fact that they repeat this assertion \\
and consequently discuss and try to prove its \\
untruthfulness based on Marx and Engels' words. It is \\
also highlighted the challenges faced by scholars \\
when they try to advance the production of ideas \\
concerning leisure. \\
Keywords: Leisure activities. State of the art. Marx. \\
Engels. Marxism. Bibliography as topic. \\
\hline
\end{tabular}

Los Estudios del Ocio en Brasil - Apropiación de la Obra de Marx y Engels

Resumen: Relato parcial de balance del estado del arte de la producción del conocimiento referente a los estudios del ocio en Brasil, correspondiente al análisis de los estudios que apropian la obra de Marx y Engels. Se destacan los diferentes modos como la obra de Marx y Engels va a ser referida e interpretada, centrándose, en este artículo, en el debate de los estudios del ocio que afirman que Marx elige el trabajo como necesidad y obligación suprema del individuo. Se exponen los estudios y los estudiosos que repiten esta afirmación para enseguida debatirlos, con el apoyo de la cita de pasajes de las obras de Marx y Engels, comprobando la falta de veracidad de esta afirmación. Se destacan los desafíos que los estudiosos deben enfrentar para promocionar el avance de la producción del conocimiento sobre la problemática del ocio.

Palabras-clave: Actividades recreativas. Estado del arte. Marx. Engels. Marxismo. Bibliografía como asunto.

\section{REFERÊNCIAS}

ALVES, Giovani Antonio Pinto. Trabalho, subjetividade e lazer: estranhamento, fetichismo e reificação no capitalismo global. In: PADILHA, Valquiria (Org.). Dialética do Lazer. São Paulo: Cortez, 2006.

Movimento, Porto Alegre, v. 14, n. 03, p. 87-116, setembro/dezembro de 2008. 
AMARAL, Silvia Cristina Franco. Políticas públicas de lazer: existe possibilidade de uma gestão participativa? In: PADILHA, Valquíria (Org.). Dialética do lazer. São Paulo: Cortez, 2006. p. 156-172.

ANDERSON, Perry. Considerações sobre o marxismo ocidental. São Paulo: Brasiliense, 1989

ANDRADE, José de. Implementação de uma política de lazer para a cooperativa do Movimento dos Trabalhadores Rurais Sem-Terra (MST): relato de pesquisa-ação. In: PADILHA, Valquíria (Org.). Dialética do lazer. São Paulo: Cortez, 2006.

ANTUNES, Ricardo. Tempo de trabalho e tempo livre: por uma vida cheia de sentido dentro e fora do trabalho In: Os sentidos do trabalho. São Paulo: Boitempo, 1999.

Tempo de trabalho e tempo livre: algumas teses para discussão. In: BRUHNS, Heloísa Turini; GUTIERREZ, Gustavo Luis. Representações do lúdico. Campinas: Autores Associados, 2001.

BECKER, Dinizar Fermiano. Uma economia política do direito ao lazer: uma primeira aproximação teórica dos fundamentos econômicos do direito ao tempo livre. In: MÜLLER, Ademir; DaCOSTA, Lamartine Pereira. (Org.). Lazer e desenvolvimento regional. Santa Cruz do Sul: EDUNISC, 2002.

BOTTOMORE, Tom. Dicionário do pensamento marxista. Rio de Janeiro: Zahar, 2001.

BRUHNS, Heloísa Turini. Lazer e motricidade: dialogando com o conhecimento. In: (Org.). Temas sobre lazer. Campinas: Autores Associados, 2000.

CAFÉ, Ângela Barcelos. O direito à cultura do lúdico. Licere, Belo Horizonte, v. 4, p. 31-45, 2001.

CAMARGO, Luiz Octávio de Lima. O lazer é um perigo. Entrevista: MAYRINK, Geraldo. Veja, São Paulo, n. 30, jun. 1993. p. 8.

A pesquisa em lazer na década de 70. In: SEMINÁRIO "O LAZER EM DEBATE" 4 , 2003, Belo Horizonte. Coletânea... Belo Horizonte: UFMG/DEF/CELAR, 2003.

Educação para o lazer. São Paulo: Moderna, 1998.

. Lazer nas empresas - tendência de um novo DRH. In: MINISTÉRIO DA EDUCAÇÃ̃O. Esporte e Lazer na Empresa. Brasília: MEC/SEED, 1990. p. 70.

CAVALCANTI, Kátia Brandão. Esporte para todos: um discurso ideológico. São Paulo: IBRASA, 1984.

CHAUÍ, Marilena de Sousa. Introdução. In: LAFARGUE, Paul. $\mathbf{O}$ direito à preguiça. São Paulo: HUCITEC/UNESP, 1999. p. 9-56.

CHEMIN, Beatris Francisca. O lazer como produto do trabalho. In: MÜLLER, Ademir; Da COSTA, Lamartine Pereira. (Org.). Lazer e trabalho: um único ou múltiplos olhares? Santa Cruz do Sul: EDUNISC, 2003.

Movimento, Porto Alegre, v. 14, n. 03, p. 87-116, setembro/dezembro de 2008. 


\section{Artigos Originais Elza Margarida de Mendonça Peixoto}

CORTELLA, Mario Sergio. Lazer, trabalho e suas relações no ambiente organizacional - Cautela com a laborlatria. In: ENCONTRO NACIONAL DE RECREAÇÃO E LAZER, 15., 2003, Santo André. Anais... Santo André: SESCSP, Prefeitura de Santo André, 2003. CD-ROM.

COSTA , Jean Henrique; MAIA, Lerson Fernando dos Santos. A questão sindical na convenção coletiva de trabalho: condições e relações de trabalho no setor hoteleiro na cidade de Natal - RN. In: ENCONTRO NACIONAL DE RECREAÇÃO E LAZER, 15., 2003, Santo André. Anais... Santo André: SESCSP, Prefeitura de Santo André, 2003. CD-ROM.

CUNHA, Newton. A felicidade imaginada: a negação do trabalho e do lazer. São Paulo: Brasiliense, 1987.

Da COSTA, Lamartine Pereira. Lazer e trabalho: um único ou múltiplos olhares? In: MÜLLER, Ademir; DaCOSTA, Lamartine Pereira. (Org.). Lazer e trabalho: um único ou múltiplos olhares? Santa Cruz do Sul: EDUNISC, 2003.

ENGELS, Friedrich. A origem da família da propriedade privada e do Estado. Rio de Janeiro: Bertrand Brasil, 1995.

Anti-Dühring. 3. ed. São Paulo: Paz e Terra, 1990. 232 p.

Dialética da natureza. 6. ed. Rio de Janeiro: Paz e Terra, 2000. 238 p.

Ludwig Feuerbach e o fim da filosofia clássica alemã. In: MARX, Karl;

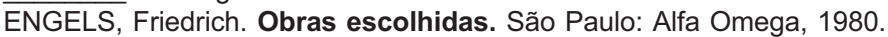

FALEIROS, Maria Isabel Leme. O lazer em questão: redefinição no modo de vida de um grupo operário. 1979. Dissertação (Mestrado) - Pontifícia Universidade Católica, São Paulo, 1979.

Repensando o lazer. Perspectiva, São Paulo, n. 3, 1980.

FERES NETO, Alfredo. A esportivização do mundo e/ou a industrialização do esporte: suas influências na vivência lúdica com a criança, em especial com o brinquedo. Motrivivência, v. 6, n. 9, p. 109-117, dez. 1996.

Fundamentos teórico-metodológicos para o estudo da mediação da experiência lúdica pela tecnologia. In: CONGRESSO BRASILEIRO DE CIÊNCIAS DO ESPORTE - CONBRACE, 10., 1997, Goiânia. Anais... Renovações, modismos e interesses. Goiânia: CBCE/Potência, 1997. v. 1, p. 522-528.

FERNANDES, Florestan. Marx e Engels: História. São Paulo: Ática, 1989.

FINOCCHIO, José Luiz. O trabalho e o tempo livre: libertação e humanização. In: ENCONTRO NACIONAL DE HISTÓRIA DO ESPORTE, LAZER E EDUCAÇÃO FÍSICA, 1., 1993, Campinas. Coletânea... Campinas: FEF/UNICAMP, 1993. p. 60-65.

FREITAS, F. M. de C. A falácia do lazer. In: llusões e devaneios: contribuição à crítica da educação física. Vitória: UFES/CEFD, 1995. p. 95-111.

Movimento, Porto Alegre, v. 14, n. 03, p. 87-116, setembro/dezembro de 2008. 
GARIGLIO, José Ângelo. A ludicidade no "jogo" de relações trabalho/escola. Movimento, Porto Alegre, v. 2, n. 3, p. 27-33, ago. 1995.

GAWRYSZEWSKI, Bruno. A luta capitalista contra o ócio: a necessidade a um lazer comunista. ENCONTRO NACIONAL DE RECREAÇÃO E LAZER, 15., 2003, Santo André. Anais... Santo André: SESCSP, Prefeitura de Santo André, 2003. CD-ROM.

GEBARA, Ademir. O Tempo na Construção do Objeto de Estudo da História do Esporte, do Lazer e da Educação Física. ENCONTRO NACIONAL DE HISTÓRIA DO ESPORTE, LAZER E EDUCAÇÃO FÍSICA, 2., 1994, Ponta Grossa. Coletânea... Ponta Grossa: Universidade Estadual de Ponta Grossa, 1994. v. 1. p. 175-189.

GOMES, Christianne Luce. Significados da recreação e lazer no Brasil: reflexões a partir da análise de experiências institucionais (1926-1964). 2003. 322 f. Tese (Doutorado) Faculdade de Educação - Universidade Federal de Minas Gerais, Belo Horizonte, 2003.

GUIMARÃES, Ailton Vitor. Abordagens do lazer e suas inter-relações com o trabalho e a tecnologia na produção acadêmica brasileira na área do lazer. 2001. Dissertação (Mestrado em Tecnologia) - Centro Federal de Educação Tecnológica de Minas Gerais, Belo Horizonte, 2001.

GUTIERREZ, Gustavo Luis. A crise de paradigmas: sai de cena o trabalho e entra o lazer? In: BRUNHS, Heloísa Turini; GUTIERREZ, Gustavo Luis. Representações do lúdico. II Ciclo de debates lazer e motricidade. Campinas: Autores Associados, Comissão de Pós-Graduação da Faculdade de Educação da UNICAMP, 2001.

HOBSBAWM, Eric. Marx e a História. In: HOBSBAWM, E. Sobre História. São Paulo: Companhia das Letras, 1998. p. 171-184.

INACIO, Humberto Luiz de Deus. O lazer do trabalhador em um contexto de transformações tecnológicas. 1997. Dissertação (Mestrado) - Universidade Federal de Santa Catarina, Florianópolis, 1997.

Os interesses contemporâneos no lazer-empresa. In: MARCELLINO, Nelson Carvalho. (Org.). Lazer \& Empresa. Campinas: Papirus 1999. v. 1, p. 149162.

INACIO, Humberto Luiz de Deus; SILVA, Ana Paula S.; PERETI, Éden S.; LIESENFELD, Patrícia $A$. Da busca pela Adrenalina à fruição das travessuras nas práticas corporais de aventura na natureza. In: CONGRESSO BRASILEIRO DE CIÊNCIAS DO ESPORTE, 14., 2005, Porto Alegre. Anais... Porto Alegre: ESEF/UFRGS, 2005. p. 3456-3465. CD-ROM.

ISAYAMA, Hélder Ferreira; MOURA, Rodrigo Caldeira Bagni. Trabalho no lazer ou lazer no trabalho: relações entre vivência de lazer e atuação profissional. In: ENCONTRO NACIONAL DE RECREAÇÃO E LAZER, 12., 2000, Balneário Camboriú. Coletânea... Balneário Camboriú: UNIVALI/Roca, 2000. p. 570-579.

LAFARGUE, Paul. O direito à preguiça. São Paulo: Kairós, 1980.

Movimento, Porto Alegre, v. 14, n. 03, p. 87-116, setembro/dezembro de 2008. 


\section{Artigos Originais Elza Margarida de Mendonça Peixoto}

Reminiscências de Marx. In: FROMM, Erich. Conceito marxista de homem. Rio de Janeiro: Zahar, 1975.

LEIRO, Augusto César Rios. Educação, lazer e relações de gênero: talhes e doxas. Motrivivência, Florianópolis, v. 13, n. 19, p. 53-68, dez 2002b.

Lazer e educação nos parques públicos em Salvador: encontros de sujeitos em espaços de cidadania. ENCONTRO NACIONAL DE RECREAÇÃO E LAZER. 14., 2002, Santa Cruz do Sul. Coletânea... Santa Cruz do Sul: UNISC, 2002a.

LÊNIN, Vladimir lilich. As três fontes e as três partes constitutivas do marxismo. São Paulo: Global, 1978.

LOPES, Maria Isabel de Souza. É pirueta pra cavar o ganha pão. Reflexão, Campinas, v. 11, n. 35, mai/ago. 1986.

MARCASSA, Luciana. A invenção do lazer: educação, cultura e tempo livre na cidade de São Paulo. (1888-1935). 2002. 204 f. Dissertação (Mestrado) Educação Brasileira - Universidade Federal de Goiânia, Goiânia, 2002.

As faces do lazer: categoria necessárias à sua compreensão. In: ENCONTRO NACIONAL DE RECREAČ̃̃O E LAZER, 15., 2003, Santo André. Anais. Santo André: SESCSP, Prefeitura de Santo André, 2003a. CD-ROM.

As faces do lazer: categorias necessárias à sua compreensão. In CONGRESSO BRASILEIRO DE CIÊNCIAS DO ESPORTE, 13., 2003, Caxambú. Anais... Caxambu: CBCE, 2003b. CD-ROM.

MARCELLINO, Nelson Carvalho. Lazer e Educação. Campinas: Papirus, 1987

Lazer e Humanização. Campinas: Papirus, 1983

Perspectivas para o lazer: mercadoria ou sinal de utopia? In: MOREIRA Wagner Wey. Educação Física e Esportes: perspectivas para o século XXI. Campinas: Papirus, 1992.

MARIN, Elizara Carolina. O lúdico na vida. Revista Conexões, São Paulo, v. 1, n.2, 1999.

MARX, Carlos. GRUNDRISSE: lineamentos fundamentales para la crítica de la economía política (1857-1858). México: Fondo de Cultura Económica, 1985. 2 v.

Los debates de la VI Dieta Renana: Debates sobre la ley castigando los robos de leña. In: MARX, Carlos; ENGELS, Federico. Obras Fundamentales: Carlos Marx: Escritos de Juventud. México: Fondo de Cultura Económica, 1982a. v.1. p. $248-283$

MARX, Karl. Crítica ao programa de Gotha. In: MARX, Karl; ENGELS, Friedrich. Obras escolhidas. São Paulo: Alfa Omega, 1980.

Crítica da filosofia do direito de Hegel - Introdução. Temas de Ciências Humanas. São Paulo: Grijalbo, 1977. p. 1-14. v. 2.

Movimento, Porto Alegre, v. 14, n. 03, p. 87-116, setembro/dezembro de 2008. 
Manuscritos econômico-filosóficos e outros textos escolhidos. In: MARX: Os pensadores. 2. ed. São Paulo: Abril Cultural, 1978.

O 18 de Brumário de Luís Bonaparte. In: Abril Cultural, 1978. (Os pensadores).

MARX. São Paulo: $\overline{1989.3 \mathrm{v} .}$

O Capital: crítica da economia política. Rio de Janeiro: Bertrand Brasil,

Trabalho alienado e superação positiva da auto-alienação humana. In: FERNANDES, Florestan. Marx e Engels: História. São Paulo: Ática, 1989.

Trabalho Estranhado (extrato). Idéias, Campinas, v. 1, p. 455-472,

MARX, Karl; ENGELS, Friedrich. A ideologia alemã. Porto: Presença; São Paulo: Martins Fontes, 1980. 2 v.

MARX, Karl; ENGELS, Friedrich. Cartas filosóficas e o manifesto comunista de 1848. São Paulo: Moraes, 1987. p. 102-116.

Obras Escolhidas. São Paulo: Alfa Ômega, 1980. 3 v.

MASCARENHAS, Fernando. Lazer e trabalho: liberdade ainda que tardia. In: SEMINÁRIO O LAZER EM DEBATE, 2. 2001, Belo Horizonte. Coletânea... Belo Horizonte: EEF/UFMG, 2001. p. 81-93. $\overline{60,2001 a}$

O lazer e o príncipe eletrônico. Licere, Belo Horizonte, v. 4, n. 1, p. 46-

Entre o ócio e o negócio: teses acerca da anatomia do lazer. 2005a. 307f. Tese (Doutorado) Faculdade de Educação Física - Universidade Estadual de Campinas, Campinas.

Exclusão social clube: problema para as políticas públicas e gestão em esportes e lazer. In: Congresso Brasileiro de Ciências do Esporte, 14, Porto Alegre. Anais... Porto Alegre: ESEF/UFRGS, 2005b. p. 65-76. CD-ROM.

Lazer e grupos sociais. Concepção e método. (Dissertação) Mestrado. Faculdade de Educação Física - UNICAMP: Campinas, 2000b.

Lazer e trabalho: liberdade ainda que tardia. In: SEMINÁRIO O LAZER EM DEBATE. 2001, Belo Horizonte. Anais... Belo Horizonte: EEF/UFMG, 2001. p. 8193.

Tempo de trabalho e tempo livre: algumas reflexões a partir do marxismo contemporâneo. Licere, Belo Horizonte, v. 3, n. 01, p. 72-89, 2000a.

Em busca do ócio perdido: idealismo, panacéia e predição histórica à sombra do lazer. In: PADILHA, Valquiria (Org.) Dialética do lazer. São Paulo: Cortez, 2006. p. 75-103.

Entre o ócio e o negócio: teses acerca da anatomia do lazer. 2005. Tese (Doutorado em Educação Física) - Universidade Estadual de Campinas, Campinas, 2005.

Movimento, Porto Alegre, v. 14, n. 03, p. 87-116, setembro/dezembro de 2008. 


\section{Artigos Originais Elza Margarida de Mendonça Peixoto}

Exclusão social clube: problema para as políticas públicas e gestão em esportes e lazer. In: CONGRESSO BRASILEIRO DE CIÊNCIAS DO ESPORTE, 14 2005, Porto Alegre. Anais... Porto Alegre: ESEF/UFRGS, 2005. p. 65-76. CD-ROM

Lazer e grupos sociais. Concepção e método. 2000. Dissertação (Mestrado) - Faculdade de Educação Física, Universidade Estadual de Campinas, Campinas, 2000.

2001.

O lazer e o príncipe eletrônico. Licere, Belo Horizonte, v. 4, n. 1, p. 46-60,

Tempo de trabalho e tempo livre: algumas reflexões a partir do marxismo contemporâneo. Licere, Belo Horizonte, v. 3, n. 1, p. 72-89, 2000.

MOTA, Marcela da Silva; SOUZA, Sueli Rosa de. Tempo livre e capitalismo: uma questão de administração ou rompimento? In: ENCONTRO NACIONAL DE RECREAÇÃO E LAZER, 12., 2000, Balneário Camburiú. Coletânea... Balneário Camburiú: UNIVALI/Roca, 2000. p. 542-549.

MWEWA, Muleka. Entretenimento, "tempo livre" e sociedade de consumo no mundo da capoeira. CONGRESSO BRASILEIRO DE CIÊNCIAS DO ESPORTE, 14., 2005 Porto Alegre. Anais... Porto Alegre: ESEF/UFRGS, 2005. p. 65-76. CD-ROM.

NASCIMENTO, Laurien Cristhine Ziem. Espaço, juventude e cultura lúdica. In: CONGRESSO BRASILEIRO DE CIÊNCIAS DO ESPORTE, 14., 2005, Porto Alegre. Anais... Porto Alegre: ESEF/UFRGS, 2005. p. 3486-3495. CD-ROM.

NAVARRO, Vera Lúcia. Trabalho, saúde e tempo livre sob os domínios do capital. In: PADILHA, Valquiria (org.) Dialética do Lazer. São Paulo: Cortez, 2006.

NETTO, José Paulo. Introdução. In: MARX, Karl. A miséria da filosofia. São Paulo: Global, 1985.

OLIVEIRA, Paulo de Salles. O tempo e a máquina: um debate entre Karl Marx e Paul Lafargue. In: WERNECK, Christianne Luce Gomes; ISAYAMA, Hélder Ferreira. SEMINÁRIO "O LAZER EM DEBATE”, 3, 2002, Belo Horizonte. Coletânea... Belo Horizonte: Universidade Federal de Minas Gerais, 2002. v. 1. p. 36-42.

Raízes solidárias: a economia, a cultura e as pessoas. In: BRUHNS, Heloísa Turini; GUTIERREZ, Gustavo Luis. Representações do lúdico. Campinas: Autores Associados/Comissão de Pós-graduação da Faculdade de Educação da UNICAMP, 2001. p. 43-57 14,1986

Tempo livre, trabalho e lutas sociais. Reflexão, Campinas, n. 35, p. 7 -

OLIVEIRA, Rogério Massarotto. Possíveis relações entre lazer e natureza na sociedade capitalista. In: CONGRESSO BRASILEIRO DE CIÊNCIAS DO ESPORTE, 14., 2005, Porto Alegre. Anais... Porto Alegre: UFRGS, 2005. CD-ROM.

PACHECO, Reinaldo Tadeu Bosculo. O lazer nas empresas: onde está o trabalhador? Revista Brasileira de Ciências do Esporte, Campinas, v. 12, n. 1/ 3, p. 249-260, 1992.

Movimento, Porto Alegre, v. 14, n. 03, p. 87-116, setembro/dezembro de 2008. 
Trabalho, lazer e educação: o que diria o velho Marx? Revista UNIFIEO, Osasco, v. 3, n. 1, jan./jun. 2001, p. 107-113.

PADILHA, Valquiria. Apontamentos para um estudo crítico sobre políticas públicas de lazer. Licere, Belo Horizonte, v. 07, n. 01, p. 65-82, 2004a.

Consumo e lazer reificado no universo onírico do shoping center. In: Dialética do lazer. São Paulo: Cortez, 2006.

Discussões sobre a redução da jornada e do tempo de trabalho. Cadernos de Sociologia, Campinas, n. 2, p. 83-104, 1997.

Se o trabalho é a doença, o lazer é o remédio? ENCONTRO NACIONAL DE RECREAÇÃO E LAZER, 15., 2003, Santo André. Anais... Santo André: SESCSP, Prefeitura de Santo André, 2003a. CD-ROM.

Se o trabalho é a doença, o lazer é o remédio?. In: MÜLLER, Ademir; DACOSTA, Lamartine Pereira. (Org.). Lazer e trabalho: um único ou múltiplos olhares? Santa Cruz do Sul: EDUNISC, 2003b. p. 243-266. 2000. v. 1

Tempo livre e capitalismo: um par imperfeito. Campinas: Alínea,

Tempo Livre. Belo Horizonte: Autêntica Editora, 2004b.

PALAFOX, Gabriel Munhoz. Capitalismo tardio e globalização: implicações do desenvolvimento tecnológico na pós-modernidade e seu impacto na educação física no Brasil. In: CONGRESSO BRASILEIRO DE CIÊNCIAS DO ESPORTE (CONBRACE), 10, 1997, Goiânia. Anais... Renovações, modismos e interesses. Goiânia: CBCE/ Potência, 1997. v. 2, p. 802-807.

PARO, Vitor Henrique. Lazer e trabalho: transformações socioculturais. In: ENCONTRO NACIONAL DE RECREAÇÃO E LAZER, 15., 2003, Santo André. Anais... Santo André: SESCSP, Prefeitura de Santo André, 2003. CD-ROM.

PEIXOTO, Elza. Levantamento do estado da arte nos estudos do lazer: (Brasil) séculos XX e XXI - alguns apontamentos. Educ. Soc. , Campinas, v. 28, n. 99,2007a. Disponível em: http://www.scielo.br/scielo.php?script=sci arttext\&pid=S010173302007000200014\&lng=pt\&nrm=iso. Acesso em: 13 dez 2007. DOI: 10.1590/ S0101-73302007000200014

Os estudos do lazer e a apropriação da obra de Marx e Engels - Maria Isabel Leme Faleiros. Movimento, Porto Alegre, v. 13, n 2, p. 197-218, 2007b.

PELLEGRIN, Ana De. Lazer, corpo e sociedade. In: PADILHA, Valquiria (org.) Dialética do Lazer. São Paulo: Cortez, 2006.

POLATO, Thelma Hoehne Peres. Lazer e trabalho: algumas reflexões a partir da ontologia do ser social. Motivivência, Florianópolis, n. 20/21, p. 139-162, 2004a.

Reflexões sobre o lazer: Contribuições da ontologia do ser social. Licere, Belo Horizonte, v. 7, n. 1, p. 54-64, 2004b.

Movimento, Porto Alegre, v. 14, n. 03, p. 87-116, setembro/dezembro de 2008. 


\section{Artigos Originais Elza Margarida de Mendonça Peixoto}

REALE, Miguel. O direito de não trabalhar. Tendência do direito do trabalho contemporâneo. São Paulo: Edições LTr, 1980.

RITTER, Alexandre Luis. Lazer e estratificação social: um estudo piloto. In: ENCONTRO NACIONAL DE RECREAÇÃO E LAZER, 15., 2003, Santo André. Anais... Santo André: SESCSP, Prefeitura de Santo André, 2003. CD-ROM.

ROCES, Wenceslao. Prólogo. In: MARX, Karl; ENGELS, Frederico. Obras Fundamentales: Engels: escritos de juventud. México: Fondo de Cultura Economica, 1981. v. 2, p. VII-XVIII.

Prólogo. In: MARX, Karl; ENGELS, Frederico. Obras Fundamentales: Carlos Marx: Escritos de Juventud. México: Fondo de Cultura Economica, 1982b. v. $1, \mathrm{p} . \mathrm{VII}-\mathrm{XVI}$.

SÁ, Kátia Oliver de. Pressupostos ontológicos dos estudos do lazer no Brasil. In: ENCONTRO NACIONAL DE RECREAÇÃO E LAZER, 15., 2003, Santo André. Anais... Santo André: SESCSP, Prefeitura de Santo André, 2003b. CD-ROOM.

Trabalho e lazer alienados: uma realidade em discussão. In: ENCONTRO NACIONAL DE RECREAÇ̃̃O E LAZER, 15, 2003, Santo André. Anais... Santo André: SESCSP, Prefeitura de Santo André, 2003d. CD-ROOM.

Lazer, trabalho e educação. Pressupostos ontológicos dos estudos do lazer no Brasil. 2003. Dissertação (Mestrado) - Faculdade de Educação, Universidade Federal da Bahia, Salvador, 2003c.

Pressupostos ontológicos dos estudos do lazer no Brasil. In: CHAVES, Marcia. (Org.). Lazer e Recreação no Currículo de Educação Física. Maceió Alagoas, 2003a. p. 155-197.

SADI, Renato Sampaio. Educação física e lazer: a centralidade do trabalho como mediação. Revista Brasileira de Ciências do Esporte, Florianópolis, v. 21, n. 1 , set 1999. p. 747-753.

SALOMÃO, Alexandre França; CARMO, Gonçalo Cassins Moreira do. Lazer e religião: nexus entre o corpo e o espírito. In: CONGRESSO BRASILEIRO DE CIÊNCIAS DO ESPORTE, 14., 2005, Porto Alegre. Anais... Porto Alegre: UFRGS, 2005. CDROM.

SANTIN, Silvino. Diversidade cultural no lazer: exclusões e marginalidade. In: ENAREL - ENCONTRO NACIONAL DE RECREAÇÃO E LAZER, 1997, Belo Horizonte. Coletânea... A diversidade cultural no lazer. Belo Horizonte: UFMG/EEF/CELAR, 1997. p. 38-50.

SAVIANI, Dermeval. Escola e democracia I: a teoria da curvatura da vara. In: 61.

. Escola e democracia. São Paulo: Autores Associados, 1987. p. 40-

SILVA, Bruno Adriano R. da. Da animação cultural ao processo de organização comunitária: dialogando com a proposta dos CIEPS. In: SEMINÁRIO O LAZER EM DEBATE, 6, 2005, Belo Horizonte. Anais... Belo Horizonte: UFMG/DEF/CELAR, 2005. p. $94-95$.

Movimento, Porto Alegre, v. 14, n. 03, p. 87-116, setembro/dezembro de 2008. 
SILVA, Maria Cecília Paula. Trabalho, lazer e vida cotidiana: pela superação da lógica do capital. In: ENCONTRO NACIONAL DE RECREAÇÃO E LAZER, 15, 2003, Santo André. Anais... Santo André: SESCSP, Prefeitura de Santo André, 2003. CDROM.

SILVA, Maurício Roberto da. A exploração do trabalho infantil e suas relações com o tempo de lazer/lúdico: quando se descansa se carrega pedra! Licere, Belo Horizonte, v. 4, n. 1, 2001. p. 9-21.

Sonhos de criança: Trabalho ou lazer. In: MARCELLINO, Nelson CarvaIho. (Org.). Lúdico, Educação e Educação Física. ljuí: Unijuí, 1999, p. 49-71.

SILVA, Maurício Roberto da. Trabalho e lazer: reflexões acerca dos sonhos das crianças brasileiras sem infância. In: VAGO, Tarcísio Mauro; SOUZA, Eustáquia Salvadora de. (Org.). Trilhas e partilhas. 2. ed. Belo Horizonte: Cultura, 1997, p. 341-367.

SILVEIRA, Juliano. A relação entre lazer e trabalho na vida cotidiana dos pescadores artesanais. SEMINÁRIO O LAZER EM DEBATE, 4., Belo Horizonte. 2005 Coletânea... Belo Horizonte: UFMG/DEF/CELAR, 2005. p. 104-112.

Seja "ativo", "pratique" lazer e (colabore com a indústria): alguns comentários sobre o programa lazer ativo (NUPAF/SESI). ENCONTRO NACIONAL DE RECREAÇÃO E LAZER, 15., 2003, Santo André. Anais... Santo André: SESCSP, Prefeitura de Santo André, 2003. CD-ROM.

SODRÉ, Francisco. As necessidades dos operários brasileiros. Revista de Estudos Brasileiros, v. 1, n. 1, jul./ago. 1938. p. 66-82.

SOUSA, Iracema Soares. Ginástica laboral: lazer ou uma tecnologia organizadora do trabalho? In: Congresso Brasileiro de Ciências do Esporte, 14., 2005, Porto Alegre. Anais... Porto Alegre: ESEF/UFRGS, 2005. p. 3466-3476. CD-ROM.

Tempo livre com lazer do trabalhador e a promessa de felicidade. 2002. Tese (Doutorado) - Universidade Federal de São Paulo, São Paulo, 2002.

SOUSA, Osman Martiniano de; SEVERINO, Peterson Trindade; OLIVEIRA, Wagner Félix de. Tempo livre ou prisão capitalista? In: ENCONTRO NACIONAL DE RECREAÇÃO E LAZER, 12., 2000, Balneário Camboriú. Coletânea... Balneário Camboriú: UNIVALI/Roca, 2000. p. 537-541.

SOUZA, Adalberto de Santos; HÚNGARO, Edson Marcelo; REQUENA, Renato; POLATO, Telma Hoehne Perez. As relações entre lazer e trabalho sob uma visão ontológica. In: ENCONTRO NACIONAL DE RECREAÇÃO E LAZER, 12, 2000, Balneário Camboriú. Coletânea... Balneário Camboriú: UNIVALI/Roca, 2000. p. 528-536.

SUSSEKIND, Arnaldo. Duração do trabalho e repousos remunerados. Rio de Janeiro: Freitas Bastos, 1950.

TAFFAREL, Celi Nelza Zulke. Lazer e projeto histórico. Impulso, São Paulo, v. 16, n. 39, p. 91-106, 2005.

Movimento, Porto Alegre, v. 14, n. 03, p. 87-116, setembro/dezembro de 2008. 


\section{Artigos Originais Elza Margarida de Mendonça Peixoto}

; SANTOS JÚNIOR, Claudio Lira; ESCOBAR, Michele Ortega. Parâmetros teórico-metodológicos para o ensino e a pesquisa em educação física \& esporte e lazer. In: CHAVES, Márcia Ferreira; GAMBOA, Silvio Sánchez. (Org.). Prática Pedagógica e Produção do Conhecimento na Educação Física \& Esporte e Lazer. Maceió: EDUFAL, 2003. p. 59-80, v. 1.

VALENTE, Edison Francisco. Lazer: tempo e espaço sociais. In: ENCONTRO NACIONAL DE HISTÓRIA DO ESPORTE, LAZER E EDUCACCÃO FÍSICA, 5., 1997, Maceió. Coletânea... Maceió: ETFAL/UNIJUÍ, 1997. p. 316-323.

VALLE, Lílian A. B. do. Lazer: senso comum, perpectiva histórica e tentativa de definição. Revista quadrimestral do mestrado em Educação da UERJ. Rio de Janeiro, v. 2, mai/dez 1987.

VERONEZ, Luiz Fernando Camargo. Lazer, movimentos sociais e políticas públicas. In: CONGRESSO BRASILEIRO DE CIÊNCIAS DO ESPORTE, 13., 2003, Caxambú. Anais... Caxambu: CBCE, 2003. CD-ROM.

VIEITEZ, C. G. Marx, o trabalho e a evolução do lazer. In: BRUHNS, Heloisa Turini. (Org.) Lazer e ciências sociais: diálogos pertinentes. São Paulo: Chronos, 2002

WERNECK, Christianne Luce Gomes. Lazer, trabalho e educação: Relações históricas, questões contemporâneas. Belo Horizonte: Editora UFMG, 2000. v. 1. $157 \mathrm{p}$

WITCZAK, Marcus Vinicius Castro. Lazer e trabalho: relação de continuidade na aposentadoria? In: MÜLLER, Ademir. DaCOSTA, Lamartine Pereira. (Org.). Lazer e trabalho: um único ou múltiplos olhares? Santa Cruz do Sul: EDUNISC, 2003.

ZINGONI, Patrícia. A descentralização e novos desafios para a política pública de lazer em Belo Horizonte. Cinergis - Revista do Departamento de Educação Física e Saúde, Santa Cruz do Sul, v. 2, n. 1, p. 45-71, 2001.

Recebido em: 13/12/2007 Aprovado em: 17/03/2008

Movimento, Porto Alegre, v. 14, n. 03, p. 87-116, setembro/dezembro de 2008. 